\title{
Prenatal pesticide exposure andPON1genotype associated with adolescent body fat distribution evaluated by dual X-ray absorptiometry (DXA)
}

\section{Citation}

Tinggaard, J., C. Wohlfahrt-Veje, S. Husby, L. Christiansen, N. E. Skakkebaek, T. K. Jensen, P. Grandjean, K. M. Main, and H. R. Andersen. 2016. "Prenatal Pesticide Exposure andPON1genotype Associated with Adolescent Body Fat Distribution Evaluated by Dual X-Ray Absorptiometry (DXA)." Andrology 4 (4) (May 26): 735-744. doi:10.1111/andr.12194.

\section{Published Version}

doi:10.1111/andr.12194

\section{Permanent link}

http://nrs.harvard.edu/urn-3:HUL.InstRepos:37221726

\section{Terms of Use}

This article was downloaded from Harvard University's DASH repository, and is made available under the terms and conditions applicable to Open Access Policy Articles, as set forth at http:// nrs.harvard.edu/urn-3:HUL.InstRepos:dash.current.terms-of-use\#OAP

\section{Share Your Story}

The Harvard community has made this article openly available.

Please share how this access benefits you. Submit a story.

Accessibility 
1 Prenatal pesticide exposure and PON1 genotype associated with adolescent body fat distribution evaluated by dual X-ray absorptiometry (DXA).

3

4

5 Jeanette Tinggaard ${ }^{1}$, Christine Wohlfahrt-Veje ${ }^{1}$, Steffen Husby ${ }^{2}$, Lene Christiansen ${ }^{3}$, Niels E

6 Skakkebæk $^{1}$, Tina K Jensen ${ }^{1,3}$, Philippe Grandjean ${ }^{3}$, Katharina M Main ${ }^{1}$, Helle R Andersen ${ }^{3}$

7

$8{ }^{1}$ Department of Growth and Reproduction, University Hospital of Copenhagen, Rigshospitalet, 9 Copenhagen, Denmark

$10{ }^{2}$ Hans Christian Andersen Children's Hospital, University of Southern Denmark, Odense, 11 Denmark

$12{ }^{3}$ Institute of Public Health, University of Southern Denmark, Odense, Denmark

15 Corresponding author:

16 Jeanette Tinggaard MD

17 Department of Growth and Reproduction, GR

18 Rigshospitalet section 5064

19 Blegdamsvej 9

20 DK-2100 Copenhagen $\varnothing$

21 Denmark

$22 \quad$ Tel +45 35455085

$23 \quad$ Fax +4535456054

24 Email: jeanette.tinggaard@ regionh.dk 


\section{Abstract}

Background Many modern pesticides have endocrine disrupting abilities and early life exposure may affect growth and disease risk later in life. Previously, we reported associations between prenatal pesticide exposure and higher childhood body fat content measured by anthropometry. The associations were affected by child PON1 Q192R genotype.

Objective We aimed to study whether prenatal pesticide exposure was still associated with body fat content and distribution in the children at puberty and the potential impact of both maternal and child PON1 Q192R genotype.

Methods A prospective cohort study of 247 children born by occupationally exposed or unexposed women (greenhouse workers and controls). Two follow-up examinations (age 10-15 and 11-16 years) included simple anthropometry, skinfold measurements, pubertal staging and blood sampling. Total and regional fat\% was determined by dual X-ray absorptiometry (DXA) at age 1015.

Results Prenatal pesticide exposure was associated with increased total, android and gynoid fat $\%$ (DXA) at age 10-15 years after adjustment for sex, socio-economic status and puberty (all0.5 standard deviation score (SDS) $\mathrm{p}<0.05$ ). Stratified by sex, the associations were significant in girls (total fat: $\beta=0.7$ SDS, android-gynoid ratio: $\beta=0.1$, both $p<0.05$ ), but not in boys. Carrying the $\mathrm{R}-$ allele (child or mother, separately, or both) augmented the differences between exposed and unexposed children (total fat: $\beta=1.0$ SDS, $\beta=0.8$ SDS, $p<0.05$, respectively and $\beta=1.2$ SDS, $\mathrm{p}<0.01)$. No exposure related differences were found if either the child or mother had the QQ wildtype. At age 11-16, exposed children tended to have a higher total fat $\%$ estimated by skinfolds than unexposed children $(\mathrm{p}=0.06)$. No significant associations between prenatal exposure and BMI or waist circumference were found.

Conclusion Prenatal pesticide exposure was associated with higher adolescent body fat content, including android fat deposition, independent of puberty. Girls appeared more susceptible than boys. Furthermore, the association depended on maternal and child PON1 Q192R genotype. 


\section{Introduction}

Endocrine disrupting chemicals (EDCs), including some pesticides, are chemicals that can interfere with the endocrine system. Some EDCs may affect endocrine pathways responsible for adipose tissue differentiation (adipogenesis) or endocrine function of adipocytes (secretion of adipocytokines that are key regulators of energy balance and insulin sensitivity) (Janesick et al, 2011). Early-life exposure to such chemicals may alter metabolic programming of adipose tissue with permanent endocrine dysfunction and increased risk of metabolic diseases, including overweight, later in life (Perera et al, 2011;Stel et al, 2015; Tang-Peronard et al, 2011).

Environmental EDC exposure therefore possibly contributes to the pathogenesis of the obesity epidemic that has emerged during the recent decades. The molecular mechanisms by which some pesticides may act as obesogens are not fully understood. Several pesticides have estrogenic or antiandrogenic properties in vitro (Andersen et al, 2002; Orton et al, 2011) which may affect fat distribution (Palmer et al, 2015). Besides, some pesticides have been found in vitro to potentiate gene expression of peroxisome proliferator-activated receptor-gamma (PPARy) and activate for instance the glucocorticoid receptor (Kim et al, 2014;Sargis et al, 2010), both being important regulators of adipose tissue differentiation and function. In experimental studies, exposure of rats to otherwise subtoxic dose levels of organophosphate insecticides during development caused abnormalities in lipid and glucose metabolism, prediabetes and excess weight gain (Lassiter et al, 2008;Slotkin, 2011). In human studies, higher child- and adulthood body mass index (BMI) has been associated with early-life exposure to persistent organochlorine pesticides such as DDT and hexachlorobenzene (Karmaus et al, 2009;Smink et al, 2008; Valvi et al, 2012) but potential associations between exposure to modern pesticides and adipose tissue accumulation has not been examined.

We conducted a prospective cohort study including children whose mothers were employed in greenhouse horticulture with exposure to pesticides prior to recognition of pregnancy and children of occupationally unexposed mothers. From this cohort we have previously reported associations between pesticide exposure in the first trimester of pregnancy and lower birth weight followed by higher BMI Z-score and body fat percentage calculated from skinfolds at school age (WohlfahrtVeje et al, 2011). These findings are in accordance with several other studies reporting an association between prenatal exposure to modern pesticides and decreased birth weight, although 
not all (Guo et al, 2014;Hanke et al, 2003;Jurewicz et al, 2005; Mayhoub et al, 2014;Rauch et al, 2012;Sagiv et al, 2007; Whyatt et al, 2004; Wolff et al, 2007). Furthermore, low birthweight has been found to be associated with increased risk of childhood overweight, in particular if followed by early catch-up growth (Baird et al, 2005;Monteiro et al, 2005;Ong et al, 2006; Stettler et al, 2010).

We have also reported that the associations between prenatal pesticide exposure and body fat content were found in those children who had a common genetic variant, a glutamine (Q) to arginine (R) substitution, at position 192 in the coding region of the PON1 gene (Andersen et al, 2012). Exposed children carrying the minor allele (R) had higher abdominal circumference, BMI Zscore and body fat percentage calculated from skinfolds at school age than unexposed children while none of these variables were significantly affected in children with the PON1 192QQ wildtype. PON1 codes for paraoxonase 1 (PON1), a multifunctional high density lipoprotein (HDL)-associated enzyme, that has esterase, lactonase and antioxidant activities (Macharia et al, 2012;Gugliucci et al, 2015). PON1 hydrolyses a range of substrates including the toxic oxon derivatives of some organophosphate insecticides and also prevents lipid oxidation (Mackness et al, 2002;Richter et al, 2010). PON1 is thereby linked to toxicity of some pesticides and atherosclerotic disease.

In this study we have followed the children during puberty to investigate whether the association between prenatal pesticide exposure and body fat content persists into adolescent age. To improve the validity of our data on body fat content, we supplemented anthropometry with dual X-ray absorptiometry (DXA), a highly accurate measure of total and regional fat percentage (\%) (Atherton et al, 2013). Furthermore, we aim to investigate the impact of both maternal and child PON1 Q192R polymorphism on this association.

\section{Materials and Methods}

\section{Study population}

This is a prospective cohort study including 247 children born between 1996 and 2001, of whom 203 children had their first clinical examination at 3 months of age and 44 additional age-matched controls were included when the children were between 6 to 11 years of age (Fig. 1). The cohort 
1 has previously been described in detail (Andersen et al, 2008; Wohlfahrt-Veje et al, 2011). In brief, we recruited pregnant women employed in greenhouses in Funen, Denmark and referred to the Department of Occupational and Environmental Medicine at Odense University Hospital for risk assessment of their working conditions and guidance for safe work practises during pregnancy.

Pesticide exposure assessment was made independently by two toxicologists with special expertise in working conditions in greenhouse horticultures. Information was obtained from detailed questionnaire-assisted interview of the pregnant women and from telephone interview of the employers. Some of the women were exposed to mixtures of pesticides in the first trimester of their pregnancy before preventive measures were taken. The women were classified as occupationally exposed if pesticides were applied in the working area more than once a month and the women handled treated plants within one week after treatment and/or the women were directly involved in applying pesticides. The women were categorized as occupationally unexposed if none of the above criteria was fulfilled. The active compounds most frequently used in the working area were the insecticides, deltamethrin, dichlorvos, dimethoate chlorpyrifos and endosulfan; the fungicides captan, chlorothalonil, fenarimol, fosetyl-aluminium and iprodion and the growth regulators daminozid, paclobutrazol, chlormequat chloride and ethephon. However, more than 100 different pesticide formulations were used and the women were exposed to a variety of different mixtures of these pesticides. A detailed list of all the pesticides used in the greenhouses is available from the corresponding author. Information on birth weight (BW), birth length (BL) and gestational age was obtained from the obstetric records. Weight-for-gestational age (WGA) was calculated according to Marsal (Marsal et al, 1996). Information on lifestyle factors (including maternal smoking during pregnancy) was obtained from a questionnaire administered at the first clinical examination of the child. Socioeconomic status (SES) was grouped into $1=$ high to $5=$ low based on parental education and occupation (Hansen, 1978).

Here we present data from follow-up examinations when the children were between 10 to 15 years of age (referred to as Puberty examination 1, performed late 2011 to early 2012) and between 11 to 16 years of age (referred to as Puberty examination 2, performed first half of 2013) (Fig. 1). At Puberty examination 1, a total of 243 children were eligible for participation ( 4 were lost to followup) and 163 accepted the invitation (participation rate $67 \%$ ). At Puberty examination 2, 229 children were eligible for participation (14 families were lost to follow-up) and 133 accepted the invitation (participation rate 58\%). 128 of the 133 children participating in Puberty examination 2 
1 also participated in Puberty examination 1. One examination sheet was lost from Puberty examination 2 leaving clinical data on 132 children.

\section{Clinical examination}

The clinical examination included measurement of height to the nearest $\mathrm{mm}$ using a portable Harpenden Stadiometer (Holtain Ltc, Crymych, United Kingdom), weight to the nearest $0.1 \mathrm{~kg}$ by electronic scale (SECA delta model 707, Hamburg, Germany), hip- and waist- circumference using a SECA measurement tape and measurement of skinfold thickness to the nearest $\mathrm{mm}$ (biceps, triceps, subscapularis, suprailiac) using a Harpenden calliper (John Bull, British Indicators LTD, Weybridge, UK). All measurements were standardised and done in triplet by the same trained paediatrician (JT), who was blinded to the exposure status. Body mass index (BMI) was calculated as weight $(\mathrm{kg})$ divided by height squared $\left(\mathrm{m}^{2}\right)$. Total body fat percentage was calculated from skinfolds by the Slaughter equation (Slaughter et al, 1988):

In girls: (1.33(triceps+subscapular) -0.013 (triceps+subscapular) $\left.{ }^{2}-2.5\right)$ or $(0.546$ (triceps+subscapular) +9.7$)$ when sum of triceps and subscapular $>35 \mathrm{~mm}$. In prepubertal boys: (1.21(triceps+subscapular) - 0.008(triceps+subscapular) $\left.{ }^{2}-1.7\right)$, in pubertal boys: $\left.(1.21 \text { (triceps+subscapular) }-0.008 \text { (triceps+subscapular })^{2}-3.4\right)$, in postpubertal boys $\left(1.21\right.$ (triceps+subscapular) $\left.-0.008(\text { triceps+subscapular })^{2}-5.5\right)$ or $(0.783$ (triceps+subscapular $)+$ 1.6) when sum of triceps and subscapular $>35 \mathrm{~mm}$.

Pubertal stage was assessed by palpation and inspection according to Tanner and Marshall (Marshall et al, 1969;Marshall et al, 1970). In girls, pubertal onset was defined as Tanner stage B2 uni- or bilaterally and/or Tanner Stage PH2. In boys, pubertal onset was defined as Tanner stage G2 and/or Tanner stage PH2. Postpuberty was defined as Tanner stage B5/G5 and PH5. A combined Tanner stage was defined as the highest of B-, G- and/or PH-stage. All clinical assessments were performed by a single trained investigator (JT). All examinations were performed blinded to information about prenatal pesticide exposure.

\section{Dual X-ray Absorptiometry}


1 A whole body DXA scan was performed (Lunar Prodigy, GE Healthcare, Madison, WI, USA) on

2 the same day as the clinical examination at Puberty examination 1. All children participating in

3 Puberty examination 1 underwent DXA. The children wore standardized light clothing. A single

4 trained investigator visually checked all scans for positioning and corrected predefined body regions

5 for analysis if necessary. Total and regional mass (g), fat mass (g) and fat percentage (\%) was

6 determined. Total fat $\%$ was expressed as total fat mass divided by total body mass. Android and

7 gynoid fat\% was expressed as android fat mass/android mass and gynoid fat mass/gynoid mass,

8 respectively. Android/gynoid fat\% ratio was calculated by simple division.

\section{Laboratory analysis}

Venous blood samples from children and mothers were collected in EDTA coated vials. After centrifugation at $2000 \mathrm{~g}$ for $10 \mathrm{~min}$. at $20^{\circ} \mathrm{C}$, buffy coat was separated and stored at $-80{ }^{\circ} \mathrm{C}$ until analysis. For PON1 genotyping, DNA was isolated from buffy coat samples and PON1 genotyped as previously described by the Taqman-based allele discrimination using the ABI Prism 7700 Sequence Detection System (Andersen et al, 2012). Q192R (rs662) polymorphisms of the PON1 gene have previously been determined for 141 children who participated in the follow-up between 6 to 11 years of age (Andersen et al, 2012). In this study Q192R (rs662) polymorphisms were determined for additional 40 children and 122 mothers. For 7 of the 163 children who underwent DXA scan blood samples for PON1 genotyping were not available.

\section{Statistical analyses}

Age and sex specific standard deviation scores (SDS) for height, weight, BMI, and total body fat\% measured by DXA were calculated according to national references (Tinggaard et al, 2014;Wohlfahrt-Veje et al, 2014). Furthermore, age and sex specific SDS for android and gynoid fat $\%$ were calculated using data from 982 healthy Danish children (425 girls) aged 8-15 years as reference (Wohlfahrt-Veje et al, 2014). Within-population Z-scores for waist circumference and total body fat percentage calculated from skinfolds were calculated by a linear regression model with waist circumference or total body fat percentage calculated from skinfolds (both $\log 10$ 
1 transformed) as dependent and age and sex as independents. The standardized residuals from these

Differences between characteristics of the exposed and unexposed children were tested by Fishers exact test (dichotomous variables) or Likelihood Ratio (categorical variables with $>$ two categories) and Mann-Whitney U test (continuous variables) because not all parameters were normally distributed.

Multiple linear regression analysis was used for association analyses between prenatal pesticide exposure and body composition outcomes. Interaction between exposure and sex or PON1 Q192R polymorphism was examined by including an interaction term in the adjusted analysis. Presence of interaction was defined at $\mathrm{p}<0.2$ due to low statistical power for detection of interaction. Analyses were stratified by sex to examine effect modification by sex or if interaction was found. The following variables were included as confounders/covariates: sex, age at examination, SES (combining SES 1, 2 and 3 into one group evening the number of cases in each group and included as dummy variables using the largest group (SES 4) as reference), and pubertal development (yes/no or Tanner Stage 1 to 5). Maternal smoking in pregnancy (yes/no) was considered, but was not included because of significant correlation with SES (Chi-square, $\mathrm{p}=0.027$ ).

Due to the low frequency of minor allele homozygosity (RR), minor allele homozygosity (RR) and heterozygosity $(\mathrm{QR})$ were combined $(\mathrm{RR} / \mathrm{QR})$. Sensitivity analyses excluding one boy with type I diabetes mellitus from the analysis did not affect the results.

All analyses were performed using IBM SPSS Statistics version 22.0. A p-value $<0.05$ was considered statistically significant.

\section{Ethics}

The study was conducted according to the Helsinki II Declaration and approved by The Regional Scientific Ethical Committees for Southern Denmark (S-20070068 and The Danish Data Protection Agency (1996-1200-154, 2007-41-0956). The families gave their informed written consent to the study. 


\section{Results}

Population characteristics, anthropometric data and DXA measurements are presented in Table 1. At Puberty examination 1, exposed children had statistically significant higher BMI (SDS), waist circumference and total body fat\% calculated from skinfolds (Z-score) and total, android and gynoid fat\% (SDS) measured by DXA (all unadjusted). Furthermore, the android/gynoid ratio was higher in exposed children compared to unexposed children. At Puberty examination 2, exposed children had a higher total fat\% calculated from skinfolds (Z-score) compared to unexposed children (unadjusted), whereas all other parameters showed similar trends as Puberty examination 1 but did not reach statistical significance. Median age, percentage of pubertal children and percentage of mothers having smoked during pregnancy were similar for exposed and unexposed children at both examinations (Table 1). However, WGA was lower in exposed children and SES was lower among parents of exposed children compared to unexposed.

After adjustment for relevant covariates, BMI (SDS) and total fat\% calculated from skinfolds (Zscore) was higher in exposed children compared to unexposed children at Puberty examination 1 (Table 2). At Puberty examination 2, difference in skinfold total fat $\%$ was borderline significant $(\mathrm{p}=0.06)$ (Table 2). No differences in waist circumference (Z-score) at any of the two examinations were found. Although the interaction term between exposure and sex was not significant, analyses stratified by sex showed that associations between prenatal exposure and skinfold total fat $\%$ remained statistically significant in girls, but not boys. Likewise, BMI was higher in exposed girls compared to unexposed girls, though of borderline significance $(\mathrm{p}=0.06)$ (Table 2$)$.

Total, android and gynoid fat\% (crude values and SDS) determined by DXA was higher among exposed children compared to unexposed children (adjusted analyses) (Table 3). The variance in fat $\%$ was greater in girls compared to boys and interaction between exposure and sex was found for unstandardized outcomes (total fat $\%: \mathrm{p}=0.16$, android fat $\%: \mathrm{p}=0.07$ and android-gynoid ratio: $\mathrm{p}=0.06$ ). When outcomes were age and sex standardized the variances were similar and the interaction term was no longer significant. However, in analyses stratified by sex, the associations between prenatal pesticide exposure and both crude and standardized outcomes remained significant in girls, but not in boys (Table 3). Furthermore, the andoid-gynoid ratio was higher in exposed girls compared to unexposed girls (Table 3). Including WGA as a covariate tended to increase the effect estimates, though not markedly (data not shown). 
1 Heterogeneity in associations between DXA body fat percentage with child and maternal PON1 Q192R polymorphism

3 The genotype frequencies for PON1 Q192R in mothers ( $\mathrm{n}=122)$ were: wildtype (QQ) $49 \%$,

4 heterozygosity (QR) $46 \%$ and homozygosity (RR) $5 \%$. The minor allele frequency was $28 \%$.

5 The genotype frequencies for PON1 Q192R in children were: QQ $52 \%$, QR $40 \%$ and RR $8 \%$. In

6 children, the minor allele frequency was $28 \%$.

$7 \quad$ PON1 Q192R genotype of the child or the mother was only associated with DXA fat\% outcome 8 measures when exposure was included in the analyses (data not shown). Furthermore, the effect of prenatal pesticide exposure depended on both maternal and child PON1 Q192R genotype, except the effect of maternal PON1 Q192R genotype on android/gynoid ratio (Table 4). Exposed children being carriers of the minor allele $(\mathrm{RR} / \mathrm{QR})$ or whose mothers were carriers of the minor allele (RR/QR) had significantly higher total, android and gynoid fat\% measured by DXA compared to unexposed children with the same genotype (Table 4). Furthermore, prenatal pesticide exposure was associated with an increased android/gynoid ratio in exposed children compared to unexposed children with the RR/QR genotype (Table 4). The mean differences between exposed and unexposed children were greater if the children were carriers of the minor allele compared to the mothers being carriers (Table 4). No differences in body fat\% between exposed and unexposed QQ children were seen (Table 4).

When child and maternal PON1 QR/RR genotype was combined, the associations between exposure and fat $\%$ were potentiated (Fig. 2A-2D; total fat: $\beta=1.2$ SD [0.4-2.1], android fat: $\beta=1.3$ SD [0.5-2.1], gynoid fat: $\beta=1.2$ SD [0.3-2.2] and android-gynoid ratio: $\beta=0.24$ [0.09-0.39]). The differences between exposed and unexposed children were not significant if just one of them carried the minor allele or if both were wildtype (Fig. 2).

Unexposed RR/QR children of RR/QR mothers had a lower fat\% SDS compared to other unexposed children (Fig 2A-2D; total fat: $\beta=0.8$ SD [0.1-1.6], android fat: $\beta=0.8$ SD [0.1-1.5], gynoid fat: $\beta=0.9 \mathrm{SD}$ [0.1-1.6] and android-gynoid ratio: $\beta=0.13$ [0.01-0.26]). Conversely, exposed $\mathrm{RR} / \mathrm{QR}$ children of RR/QR mothers had a higher android/gynoid ratio compared to other exposed children $(\beta=0.11[0.02-0.20])$ (Fig. 2D). 


\section{Discussion with conclusions}

2 Prenatal pesticide exposure was associated with an increase of body fat measured by DXA and

3 skinfolds in pubertal children born by greenhouse workers who carried the minor allele of the PON1 Q192R polymorphism. These findings are in agreement with our previous findings when the children were 6 to 11 years old and suggest a long-term effect on body composition. The increment in body fat percentage estimated by skinfolds was lower than observed in the same cohort of children when examined during childhood, which suggests an impact of puberty and age (Taylor $e t$ $a l, 2010)$. To our knowledge, this is the first study to describe total and regional fat percentage measured by DXA in pubertal children prenatally exposed to pesticides. Fat estimates based on DXA are more accurate than standard anthropometry (Atherton et al, 2013)which may explain why associations were more pronounced in DXA outcomes compared with simple anthropometry such as waist circumference.

The exposure related differences in body fat percentages were more pronounced in girls than boys, suggesting a sex-specific susceptibility to metabolic disturbances after prenatal pesticide exposure. Alternatively, the discrepancy between girls and boys could be related to the higher fat mass in girls by itself, more clearly demarcating effects of exposure. Similar observations have been reported from other human studies examining the association between prenatal or early exposure to persistent organochlorines such as polychlorinated biphenyls (PCBs) and DDT and childhood obesity (Gladen et al, 2000;Hertz-Picciotto et al, 2005;Valvi et al, 2012)). We previously reported earlier breast development among the exposed girls in this cohort compared to unexposed girls (Wohlfahrt-Veje et al, 2012). Thus, prenatal pesticide exposure may affect both fat mass and pubertal development which are known to be interlinked. However, including puberty as a confounder in the sex stratified analyses did not substantially alter the effect estimates in girls (Table 3).

The estimated mean total fat $\%$ in exposed girls/boys was $28.7 \% / 21.4 \%$ compared to $22.5 \% / 20.1 \%$ in unexposed girls/boys, respectively. In comparison, average fat percentage in this age group is $22 \%$ for girls and $17 \%$ for boys (Wohlfahrt-Veje et al, 2014). We hypothesize that this increase in body fat may be clinically relevant in girls as accumulation of adipose tissue is accompanied by dysfunctional adipocytes and may have detrimental metabolic implications (Ali et al, 2013). Furthermore, prenatal exposure tended to be associated with a larger degree of abdominal (android) than peripheral (gynoid) fat accumulation, reflected by the higher android/gynoid ratio. Abdominal 
1 adiposity is associated with an increased risk of metabolic and cardiovascular disease independently of BMI both in adults and children (Gishti et al, 2015;Oliveros et al, 2014). Though peripheral fat, which may be protective for metabolic disease, was also increased in exposed children, the android/gynoid ratio was shifted towards a metabolically unhealthy profile in girls (Gishti et al, 2015). Furthermore, android/gynoid ratio may be a better predictor of metabolic and cardiovascular disease risk in children than android fat\% itself, emphasising the importance of assessing fat distribution (Samsell et al, 2014;Zong et al, 2015). Therefore these findings are of particular concern.

As previously reported (Wohlfahrt-Veje et al, 2011), WGA was lower in exposed children than unexposed children and as low WGA, especially followed by rapid infancy growth, is associated with childhood obesity (Stettler et al, 2010;Ong et al, 2006) the effect of prenatal pesticide exposure may be mediated by this. However, including WGA in the analyses tended to increase rather than decrease the estimates of the association between prenatal pesticide exposure and pubertal fat content. This supports an independent effect of exposure on body fat accumulation.

We have previously reported a gene-environment interaction between child PON1 Q192R genotype and prenatal pesticide exposure on body fat content estimated by anthropometry among the children at 6 to 11 years of age (Andersen et al, 2012). This pubertal follow-up confirms the geneenvironment interaction, since body fat accumulation was only enhanced if either the child or the mother or both carried the PON1 192R-allele. Hence, the differential effects on body fat content related to child PON1 gene heterogeneities persisted into puberty. In addition, we found that also the maternal PON1 Q192R genotype affected the associations. Mothers carrying the R-allele may detoxify some pesticides more slowly and have reduced anti-oxidative capacity to protect against lipid oxidation, resulting in a more unhealthy metabolic profile (Aviram et al, 2000;Costa et al, 2015; Macharia et al, 2012). This might result in a more adverse intrauterine environment affecting metabolic programming. Furthermore, although the expression of the PON1 gene is low in newborns and probably also in fetal life, the fetal PON1 genotype may be associated with epigenetic changes, such as DNA-methylation in the PON1 gene, thereby altering PON1 expression and related risk profile later in life (Huen et al, 2015;Liu et al, 2013) Our findings of a larger effect of prenatal exposure if both the child and the mother carried the R-allele suggests for an additive effect. 
1 We found that unexposed children had a significantly lower total and regional body fat $\%$ if both the child and the mother carried the minor allele compared to other unexposed children. This finding accounts for part of the larger difference in body fat $\%$ between exposed and unexposed $Q R / R R$ children of QR/RR mothers. However, this may be a chance finding due to the limited number of children in each subgroup. Therefore, these findings should be interpreted with caution and needs to be replicated in a larger cohort study.

Among women working in floricultures in Mexico, those with the PON1 192RR genotype had higher risk of miscarriage (Blanco-Munoz et al, 2013) and having children with low birth weight than women with the QQ or QR genotype (Moreno-Banda et al, 2009). In contrast, maternal PON1 Q192R genotype did not affect the association between maternal organophosphate concentration during pregnancy and child birth outcome measures in the Chamacos Study, nor did it affect the PON1 activity in the child. In this cohort, child PON1 wildtype was associated with childhood obesity at age 2 years, but possible effects of pesticide exposure was not included (Huen et al, 2013). The effect of PON1 genotype is complex. PON1 Q192R genotype contributes only partly to the variance in PON1 activity, PON1 activity varies with age (Harley et al, 2011;Huen et al, 2009; Huen et al, 2010) and distribution of PON1 Q192R polymorphism varies with ethnicity (Huen et al, 2013). These factors all complicate study comparison along with differences in type, timing and level of exposure and likely account for some of the discrepant results. In our study, the mothers were exposed to a variety of different pesticides including organophosphates and several fungicides with known endocrine disrupting properties. Due to the complex exposure setting it was not possible to identify specific pesticides as responsible for the effects. However, mixed exposure is a real-world situation and the effects may very well be related to combined exposures to several pesticides. PON1 is known to detoxify toxic oxon derivatives of some organophosphate insecticides and organophosphates were used occasionally in the working areas for most of the exposed mothers. However, only very few mothers had been involved directly in their application. Whether PON1 can detoxify other types of pesticides than organophosphates has, to our knowledge, not yet been investigated. The mothers were only occupationally exposed to pesticides until 8 to 12 weeks of gestation. The first weeks of gestation is a period of high vulnerability to interference with epigenetic reprogramming and exposure may have detrimental health effects for the unborn child (Perera et al, 2011). However, epigenetic changes occurs throughout life (Perera et al, 2011) and may counterbalance part of the adverse effects of prenatal exposure. 
1 Limitations to this cohort study include the relatively small sample size and potential selection bias

2 introduced by loss of children to follow-up and inclusion of additional controls. These limitations

3 have been addressed in previous publication (Andersen et al, 2012; Wohlfahrt-Veje et al, 2011).

4 Although the association between prenatal exposure and outcome measurements are consistent, use

5 of exposure biomarkers would have strengthened our findings. However, our study design did not

6 allow bio-monitoring of pesticide exposure in the mothers and the exposure classification

7 encompassed more than 100 pesticides used in different mixtures. The blinded exposure

8 classification, the blinded clinical examinations and the longitudinal design minimize the possible

9 impact of exposure misclassification and bias. Diet and physical activity are relevant covariates,

10 which we were not able to adjust for. However, we include SES in our analyses which may partly

11 adjust for these factors because SES and lifestyle are correlated. Other possible confounders are

12 maternal pre-pregnancy BMI and gestational weight gain, which this study lacks information on.

13 Furthermore, some of the mothers resumed working in greenhouses after maternity leave and take-

14 home exposure in these cases cannot be excluded. However, we do not have valid information for the relevant period allowing us to adjust for this.

In conclusion, prenatal exposure to non-persistent pesticides was associated with long-term increase in body fat percentage, especially of android fat, during puberty. Girls seemed more susceptible than boys and the effect of prenatal exposure also depended on maternal and child PON1 Q192R genotype, indicating complex interactions between sex, prenatal environment and genetics.

Acknowledgements

We are very grateful to all families, children and adolescents who participated in this study. We also appreciate the skilled help from assistants and students (Hans Christian Andersen Children's Hospital and Institute of Public Health, University of Southern Denmark, Odense, Denmark) 
1 The study was funded by The Danish Environmental Protection Agency and The Danish Council

2 for Strategic Research. The funding organization played no role in study design or conduction, in

3 collecting, analyzing or interpreting data.

\section{Disclosures}

8 The authors have nothing to disclose

9

\section{Authors' contributions}

Jeanette Tinggaard: writing of the manuscript, literature search, study design, data collection, data analyses, data interpretation, tables and figures.

Christine Wohlfahrt-Veje, Steffen Husby, Lene Christiansen, Niels E Skakkebæk, Tina K Jensen, Philippe Grandjean: Study design, data interpretation, data analyses, writing of manuscript. Lene Christiansen also contributed in data collection.

Helle R Andersen: Supervision, study design, data collection, data interpretation, data analyses, writing of manuscript.

Katharina M Main: Supervision, study design, data interpretation, data analyses, writing of manuscript. 
Reference List

2

1. Ali, A. T., Hochfeld, W. E., Myburgh, R., and Pepper, M. S. (2013). Adipocyte and adipogenesis. Eur.J.Cell Biol. 92, 229-236.

2. Andersen, H. R., Schmidt, I. M., Grandjean, P., Jensen, T. K., Budtz-Jorgensen, E., Kjaerstad, M. B., Baelum, J., Nielsen, J. B., Skakkebaek, N. E., and Main, K. M. (2008). Impaired reproductive development in sons of women occupationally exposed to pesticides during pregnancy. Environ.Health Perspect. 116, 566-572.

3. Andersen, H. R., Vinggaard, A. M., Rasmussen, T. H., Gjermandsen, I. M., and BonefeldJorgensen, E. C. (2002). Effects of currently used pesticides in assays for estrogenicity, androgenicity, and aromatase activity in vitro. Toxicol.Appl.Pharmacol. 179, 1-12.

4. Andersen, H. R., Wohlfahrt-Veje, C., Dalgard, C., Christiansen, L., Main, K. M., Nellemann, C., Murata, K., Jensen, T. K., Skakkebaek, N. E., and Grandjean, P. (2012). Paraoxonase 1 polymorphism and prenatal pesticide exposure associated with adverse cardiovascular risk profiles at school age. PLoS.One. 7, e36830.

5. Atherton, R. R., Williams, J. E., Wells, J. C., and Fewtrell, M. S. (2013). Use of fat mass and fat free mass standard deviation scores obtained using simple measurement methods in healthy children and patients: comparison with the reference 4-component model. PLoS.One. 8, e62139.

6. Aviram, M., Hardak, E., Vaya, J., Mahmood, S., Milo, S., Hoffman, A., Billicke, S., Draganov, D., and Rosenblat, M. (2000). Human serum paraoxonases (PON1) Q and R selectively decrease lipid peroxides in human coronary and carotid atherosclerotic lesions: PON1 esterase and peroxidase-like activities. Circulation 101, 2510-2517.

7. Baird, J., Fisher, D., Lucas, P., Kleijnen, J., Roberts, H., and Law, C. (2005). Being big or growing fast: systematic review of size and growth in infancy and later obesity. BMJ 331, 929.

8. Blanco-Munoz, J., Aguilar-Garduno, C., Gamboa-Avila, R., Rodriguez-Barranco, M., PerezMendez, O., Huesca-Gomez, C., Gonzalez-Alzaga, B., and Lacasana, M. (2013). Association between PON1 genetic polymorphisms and miscarriage in Mexican women exposed to pesticides. Sci.Total Environ. 449, 302-308.

9. Costa, C., Gangemi, S., Giambo, F., Rapisarda, V., Caccamo, D., and Fenga, C. (2015). Oxidative stress biomarkers and paraoxonase 1 polymorphism frequency in farmers occupationally exposed to pesticides. Mol.Med.Rep. 12, 6353-6357.

10. Gishti, O., Gaillard, R., Durmus, B., Abrahamse, M., van der Beek, E. M., Hofman, A., Franco, O. H., de Jonge, L. L., and Jaddoe, V. W. (2015). BMI, total and abdominal fat distribution, and cardiovascular risk factors in school-age children. Pediatr.Res. 77, 710-718. 
11. Gladen, B. C., Ragan, N. B., and Rogan, W. J. (2000). Pubertal growth and development and prenatal and lactational exposure to polychlorinated biphenyls and dichlorodiphenyl dichloroethene. J.Pediatr. 136, 490-496.

12. Gugliucci, A., and Menini, T. (2015). Paraoxonase 1 and HDL maturation. Clin.Chim.Acta 439, 5-13.

13. Guo, H., Jin, Y., Cheng, Y., Leaderer, B., Lin, S., Holford, T. R., Qiu, J., Zhang, Y., Shi, K., Zhu, Y., Niu, J., Bassig, B. A., Xu, S., Zhang, B., Li, Y., Hu, X., Chen, Q., and Zheng, T. (2014). Prenatal exposure to organochlorine pesticides and infant birth weight in China. Chemosphere 110, 1-7.

14. Hanke, W., Romitti, P., Fuortes, L., Sobala, W., and Mikulski, M. (2003). The use of pesticides in a Polish rural population and its effect on birth weight.

Int.Arch.Occup.Environ.Health 76, 614-620.

15. Hansen, E. J. The Distribution of the Living Conditions in Denmark. 17-65. 1978.

Copenhagen, The Danish National Institute of Social Research.

16. Harley, K. G., Huen, K., Aguilar, S. R., Holland, N. T., Bradman, A., Barr, D. B., and Eskenazi, B. (2011). Association of organophosphate pesticide exposure and paraoxonase with birth outcome in Mexican-American women. PLoS.One. 6, e23923.

17. Hertz-Picciotto, I., Charles, M. J., James, R. A., Keller, J. A., Willman, E., and Teplin, S. (2005). In utero polychlorinated biphenyl exposures in relation to fetal and early childhood growth. Epidemiology 16, 648-656.

18. Huen, K., Harley, K., Beckman, K., Eskenazi, B., and Holland, N. (2013). Associations of PON1 and genetic ancestry with obesity in early childhood. PLoS.One. 8, e62565.

19. Huen, K., Harley, K., Bradman, A., Eskenazi, B., and Holland, N. (2010). Longitudinal changes in PON1 enzymatic activities in Mexican-American mothers and children with different genotypes and haplotypes. Toxicol.Appl.Pharmacol. 244, 181-189.

20. Huen, K., Harley, K., Brooks, J., Hubbard, A., Bradman, A., Eskenazi, B., and Holland, N. (2009). Developmental changes in PON1 enzyme activity in young children and effects of PON1 polymorphisms. Environ.Health Perspect. 117, 1632-1638.

21. Huen, K., Yousefi, P., Street K, Eskenazi, B., and Holland, N. PON1 as a model for integration of genetic, epigenetic, and expression data on candidate susceptibility genes. Environmental Epigenetics 1(1):dvv003, 1-11. 2015. Environmental Epigenetics.

22. Janesick, A., and Blumberg, B. (2011). Endocrine disrupting chemicals and the developmental programming of adipogenesis and obesity. Birth Defects Res.C.Embryo.Today 93, 34-50.

23. Jurewicz, J., Hanke, W., Makowiec-Dabrowska, T., and Sobala, W. (2005). Exposure to pesticides and heavy work in greenhouses during pregnancy: does it effect birth weight? Int.Arch.Occup.Environ.Health 78, 418-426. 
24. Karmaus, W., Osuch, J. R., Eneli, I., Mudd, L. M., Zhang, J., Mikucki, D., Haan, P., and Davis, S. (2009). Maternal levels of dichlorodiphenyl-dichloroethylene (DDE) may increase weight and body mass index in adult female offspring. Occup.Environ.Med. 66, 143-149.

25. Kim, J., Park, Y., Yoon, K. S., Clark, J. M., and Park, Y. (2014). Permethrin alters adipogenesis in 3T3-L1 adipocytes and causes insulin resistance in $\mathrm{C} 2 \mathrm{C} 12$ myotubes. J.Biochem.Mol.Toxicol. 28, 418-424.

26. Lassiter, T. L., and Brimijoin, S. (2008). Rats gain excess weight after developmental exposure to the organophosphorothionate pesticide, chlorpyrifos. Neurotoxicol.Teratol. 30 , 125-130.

27. Liu, M. E., Liao, Y. C., Lin, R. T., Wang, Y. S., Hsi, E., Lin, H. F., Chen, K. C., and Juo, S. H. (2013). A functional polymorphism of PON1 interferes with microRNA binding to increase the risk of ischemic stroke and carotid atherosclerosis. Atherosclerosis 228, 161-167.

28. Macharia, M., Hassan, M. S., Blackhurst, D., Erasmus, R. T., and Matsha, T. E. (2012). The growing importance of PON1 in cardiovascular health: a review. J.Cardiovasc.Med.(Hagerstown.) 13, 443-453.

29. Mackness, M. I., Mackness, B., and Durrington, P. N. (2002). Paraoxonase and coronary heart disease. Atheroscler.Suppl 3, 49-55.

30. Marsal, K., Persson, P. H., Larsen, T., Lilja, H., Selbing, A., and Sultan, B. (1996). Intrauterine growth curves based on ultrasonically estimated foetal weights. Acta Paediatr. 85, 843-848.

31. Marshall, W. A., and Tanner, J. M. (1969). Variations in pattern of pubertal changes in girls. Arch.Dis.Child 44, 291-303.

32. Marshall, W. A., and Tanner, J. M. (1970). Variations in the pattern of pubertal changes in boys. Arch.Dis.Child 45, 13-23.

33. Mayhoub, F., Berton, T., Bach, V., Tack, K., Deguines, C., Floch-Barneaud, A., Desmots, S., Stephan-Blanchard, E., and Chardon, K. (2014). Self-Reported Parental Exposure to Pesticide during Pregnancy and Birth Outcomes: The MecoExpo Cohort Study. PLoS.One. 9, e99090.

34. Monteiro, P. O., and Victora, C. G. (2005). Rapid growth in infancy and childhood and obesity in later life--a systematic review. Obes.Rev. 6, 143-154.

35. Moreno-Banda, G., Blanco-Munoz, J., Lacasana, M., Rothenberg, S. J., Aguilar-Garduno, C., Gamboa, R., and Perez-Mendez, O. (2009). Maternal exposure to floricultural work during pregnancy, PON1 Q192R polymorphisms and the risk of low birth weight. Sci.Total Environ. 407, 5478-5485.

36. Oliveros, E., Somers, V. K., Sochor, O., Goel, K., and Lopez-Jimenez, F. (2014). The concept of normal weight obesity. Prog.Cardiovasc.Dis. 56, 426-433.

37. Ong, K. K., and Loos, R. J. (2006). Rapid infancy weight gain and subsequent obesity: systematic reviews and hopeful suggestions. Acta Paediatr. 95, 904-908. 
38. Orton, F., Rosivatz, E., Scholze, M., and Kortenkamp, A. (2011). Widely used pesticides with previously unknown endocrine activity revealed as in vitro antiandrogens. Environ.Health Perspect. 119, 794-800.

39. Palmer, B. F., and Clegg, D. J. (2015). The sexual dimorphism of obesity. Mol.Cell Endocrinol. 402, 113-119.

40. Perera, F., and Herbstman, J. (2011). Prenatal environmental exposures, epigenetics, and disease. Reprod.Toxicol. 31, 363-373.

41. Rauch, S. A., Braun, J. M., Barr, D. B., Calafat, A. M., Khoury, J., Montesano, A. M., Yolton, K., and Lanphear, B. P. (2012). Associations of prenatal exposure to organophosphate pesticide metabolites with gestational age and birth weight. Environ.Health Perspect. 120, 1055-1060.

42. Richter, R. J., Jarvik, G. P., and Furlong, C. E. (2010). Paraoxonase 1 status as a risk factor for disease or exposure. Adv.Exp.Med.Biol. 660, 29-35.

43. Sagiv, S. K., Tolbert, P. E., Altshul, L. M., and Korrick, S. A. (2007). Organochlorine exposures during pregnancy and infant size at birth. Epidemiology 18, 120-129.

44. Samsell, L., Regier, M., Walton, C., and Cottrell, L. (2014). Importance of android/gynoid fat ratio in predicting metabolic and cardiovascular disease risk in normal weight as well as overweight and obese children. J.Obes. 2014, 846578.

45. Sargis, R. M., Johnson, D. N., Choudhury, R. A., and Brady, M. J. (2010). Environmental endocrine disruptors promote adipogenesis in the 3T3-L1 cell line through glucocorticoid receptor activation. Obesity.(Silver.Spring) 18, 1283-1288.

46. Slaughter, M. H., Lohman, T. G., Boileau, R. A., Horswill, C. A., Stillman, R. J., Van, L., and Bemben, D. A. (1988). Skinfold equations for estimation of body fatness in children and youth. Hum.Biol. 60, 709-723.

47. Slotkin, T. A. (2011). Does early-life exposure to organophosphate insecticides lead to prediabetes and obesity? Reprod.Toxicol. 31, 297-301.

48. Smink, A., Ribas-Fito, N., Garcia, R., Torrent, M., Mendez, M. A., Grimalt, J. O., and Sunyer, J. (2008). Exposure to hexachlorobenzene during pregnancy increases the risk of overweight in children aged 6 years. Acta Paediatr. 97, 1465-1469.

49. Stel, J., and Legler, J. (2015). The Role of Epigenetics in the Latent Effects of Early Life Exposure to Obesogenic Endocrine Disrupting Chemicals. Endocrinology 156, 3466-3472.

50. Stettler, N., and Iotova, V. (2010). Early growth patterns and long-term obesity risk. Curr.Opin.Clin.Nutr.Metab Care 13, 294-299.

51. Tang-Peronard, J. L., Andersen, H. R., Jensen, T. K., and Heitmann, B. L. (2011). Endocrinedisrupting chemicals and obesity development in humans: a review. Obes.Rev. 12, 622-636. 
52. Taylor, R. W., Grant, A. M., Williams, S. M., and Goulding, A. (2010). Sex differences in regional body fat distribution from pre- to postpuberty. Obesity.(Silver.Spring) 18, 1410-1416.

53. Tinggaard, J., Aksglaede, L., Sorensen, K., Mouritsen, A., Wohlfahrt-Veje, C., Hagen, C. P., Mieritz, M. G., Jorgensen, N., Wolthers, O. D., Heuck, C., Petersen, J. H., Main, K. M., and Juul, A. (2014). The 2014 Danish references from birth to 20 years for height, weight and body mass index. Acta Paediatr. 103, 214-224.

54. Valvi, D., Mendez, M. A., Martinez, D., Grimalt, J. O., Torrent, M., Sunyer, J., and Vrijheid, M. (2012). Prenatal concentrations of polychlorinated biphenyls, DDE, and DDT and overweight in children: a prospective birth cohort study. Environ.Health Perspect. 120, 451457.

55. Whyatt, R. M., Rauh, V., Barr, D. B., Camann, D. E., Andrews, H. F., Garfinkel, R., Hoepner, L. A., Diaz, D., Dietrich, J., Reyes, A., Tang, D., Kinney, P. L., and Perera, F. P. (2004). Prenatal insecticide exposures and birth weight and length among an urban minority cohort. Environ.Health Perspect. 112, 1125-1132.

56. Wohlfahrt-Veje, C., Andersen, H. R., Schmidt, I. M., Aksglaede, L., Sorensen, K., Juul, A., Jensen, T. K., Grandjean, P., Skakkebaek, N. E., and Main, K. M. (2012). Early breast development in girls after prenatal exposure to non-persistent pesticides. Int.J.Androl 35, 273282.

57. Wohlfahrt-Veje, C., Main, K. M., Schmidt, I. M., Boas, M., Jensen, T. K., Grandjean, P., Skakkebaek, N. E., and Andersen, H. R. (2011). Lower birth weight and increased body fat at school age in children prenatally exposed to modern pesticides: a prospective study. Environ.Health 10, 79.

58. Wohlfahrt-Veje, C., Tinggaard, J., Winther, K., Mouritsen, A., Hagen, C. P., Mieritz, M. G., de Renzy-Martin, K. T., Boas, M., Petersen, J. H., and Main, K. M. (2014). Body fat throughout childhood in 2647 healthy Danish children: agreement of BMI, waist circumference, skinfolds with dual X-ray absorptiometry. Eur.J.Clin.Nutr. 68, 664-670.

59. Wolff, M. S., Engel, S., Berkowitz, G., Teitelbaum, S., Siskind, J., Barr, D. B., and Wetmur, J. (2007). Prenatal pesticide and PCB exposures and birth outcomes. Pediatr.Res. 61, 243-250.

60. Zong, G., Grandjean, P., Wu, H., and Sun, Q. (2015). Circulating persistent organic pollutants and body fat distribution: Evidence from NHANES 1999-2004. Obesity.(Silver.Spring) 23, 1903-1910. 
Table 1 Population characteristics, anthropometric data and DXA data in children participating in Puberty examination 1 and 2.

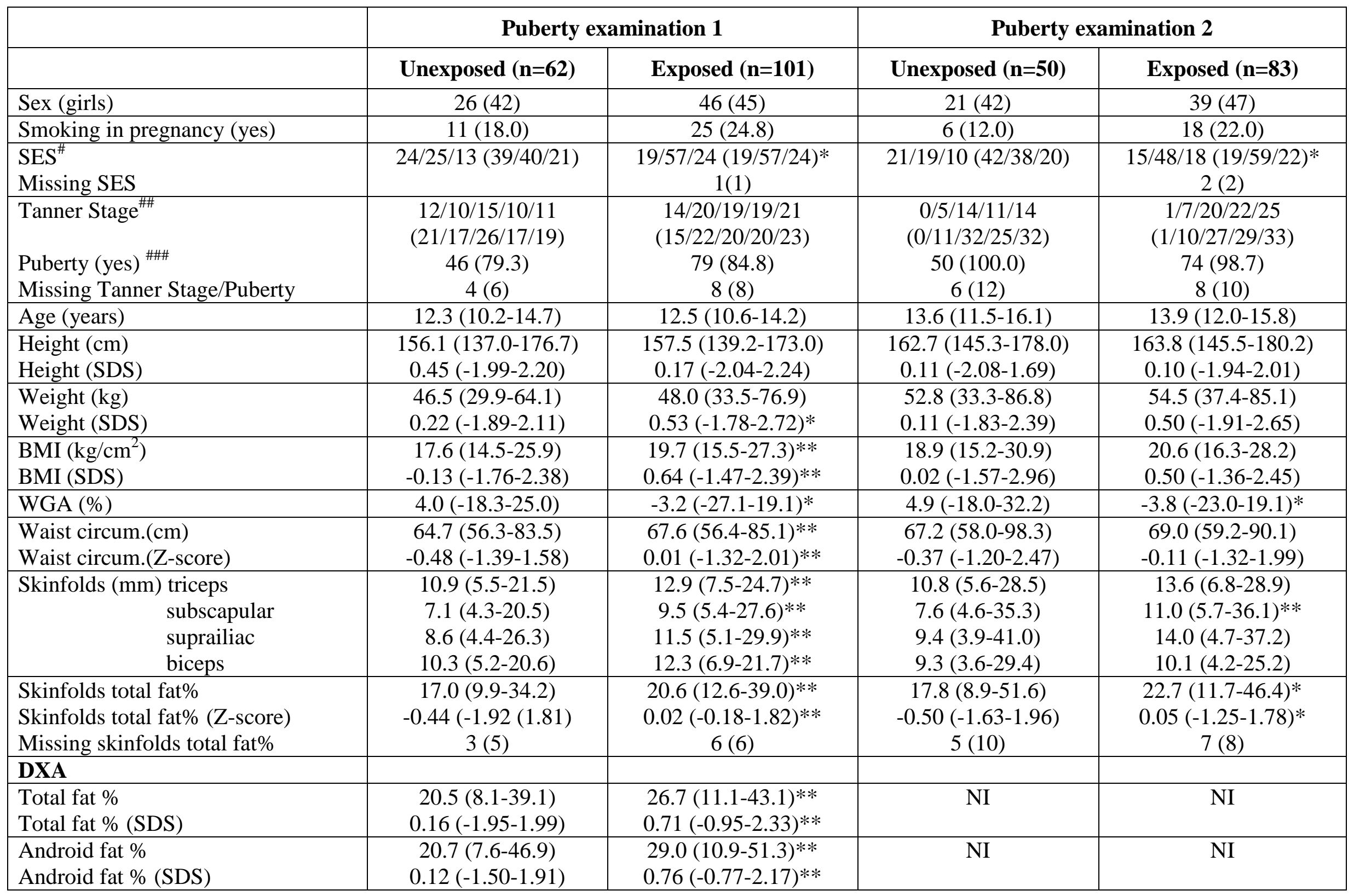




\begin{tabular}{|l|c|c|c|c|}
\hline Gynoid fat \% & $32.8(12.6-49-1)$ & $38.1(19.3-51.9)^{* *}$ & NI & NI \\
Gynoid fat \% (SDS) & $0.18(-2.04-2.15)$ & $0.74(-0.97-2.51)^{* *}$ & & \\
\hline Android/gynoid ratio & $0.66(0.48-1.03$ & $0.79(0.48-1.07)^{*}$ & NI & NI \\
\hline
\end{tabular}


Values are presented as median (5-95 percentiles) for continuous variables and as $n(\%)$ for categorical variables. Differences between unexposed and exposed children are tested using Mann-Whitney U-test for continuous variables and Fishers exact test (dichotomous variables) or Likelihood Ratio (categorical variables with $>2$ categories).

* p-value $<0.05$

$* *$ p-value $<0.01$

\# SES: Socioeconomic status (social class 1-3/4/5)

\#\# Highest of Tanner Pubic Hair stage, Tanner Breast stage (girls) and/or Tanner Genital stage (boys)

\#\#\# Tanner Stage > 1

SDS: Standard Deviation Score

NI: not investiged

Table 2 Associations between prenatal pesticide exposure and anthropometric measurements in Puberty examination 1 and $2 . \beta$ represents adjusted difference $(95 \% \mathrm{CI})$ in outcome variable between exposed and unexposed children.

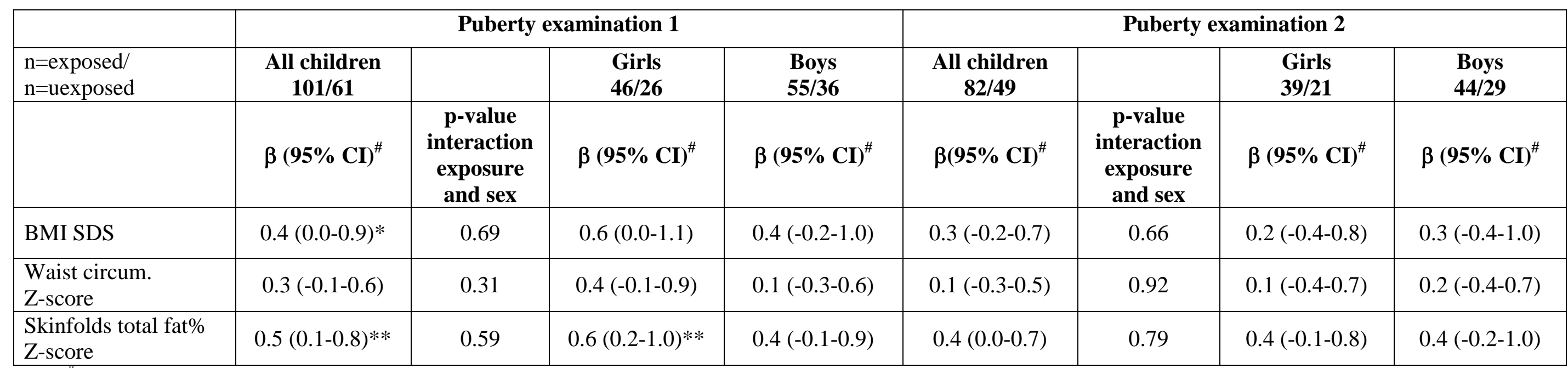

\# adjusted for sex (all children), Tanner Stage and SES

$*$ p-value $<0.05$

$* *$ p-value $<0.01$ 
Table 3 Associations between prenatal pesticide exposure and fat $\%$ measured by DXA in Puberty examination $1 . \beta$ represent adjusted mean differences (95\% CI) in outcome variables between exposed and unexposed children.

\begin{tabular}{|l|c|c|c|c|}
\hline & $\begin{array}{c}\text { All children } \\
\mathbf{1 0 1 / 6 2}\end{array}$ & & $\begin{array}{c}\text { Girls } \\
\mathbf{4 6 / 2 6}\end{array}$ & $\begin{array}{c}\text { Boys } \\
\mathbf{5 5 / 3 6}\end{array}$ \\
\hline & $\boldsymbol{\beta}(\mathbf{9 5 \%} \mathbf{C I})^{\#}$ & $\begin{array}{c}\text { P-value for } \\
\text { interaction exposure } \\
\text { and sex }\end{array}$ & $\boldsymbol{\beta}(\mathbf{9 5 \%} \mathbf{C I})^{\#}$ & $\boldsymbol{\beta}(\mathbf{9 5 \%} \mathbf{C I})^{\#}$ \\
\hline Total fat \% & $3.80(0.76-6.84)^{*}$ & 0.16 & $6.18(1.82-10.54)^{* *}$ & $1.33(-3.15-5.82)$ \\
Total fat \% SDS & $0.53(0.17-0.89)^{* *}$ & 0.43 & $0.73(0.20-1.27)^{* *}$ & $0.39(-0.11-0.89)$ \\
\hline Android fat \% & $4.50(0.39-8.62)^{*}$ & 0.07 & $8.66(2.74-14.59)^{* *}$ & $0.56(-5.53-6.66)$ \\
Android fat \% SDS & $0.45(0.10-0.79)^{*}$ & 0.29 & $0.67(0.16-1.18)^{*}$ & $0.28(-0.20-0.75)$ \\
\hline Gynoid fat\% & $4.11(1.05-7.17)^{* *}$ & 0.38 & $5.49(1.58-9.40)^{* *}$ & $2.19(-2.63-6.99)$ \\
Gynoid fat \% SDS & $0.54(0.16-0.92)^{* *}$ & 0.47 & $0.75(0.19-1.32)^{* *}$ & $0.40(-0.13-0.93)$ \\
\hline Android/Gynoid ratio & $0.04(-0-02-0.10)$ & 0.06 & $0.11(0.02-0.20)^{*}$ & $-0.01(-0.10-0.08)$ \\
\hline
\end{tabular}

${ }^{\#}$ Absolute values adjusted for sex (all children), age, SES and puberty (yes/no).

SDS adjusted for sex (all children), SES and puberty (yes/no).

$*$ p-value $<0.05$

$* *$ p-value $<0.01$ 
Table 4 Associations between prenatal pesticide exposure and fat $\%$ measured by DXA stratified by child or maternal PON1 Q192R genotype. $\beta$ represent adjusted mean differences $(95 \% \mathrm{CI})$ in outcome variables between exposed and unexposed children.

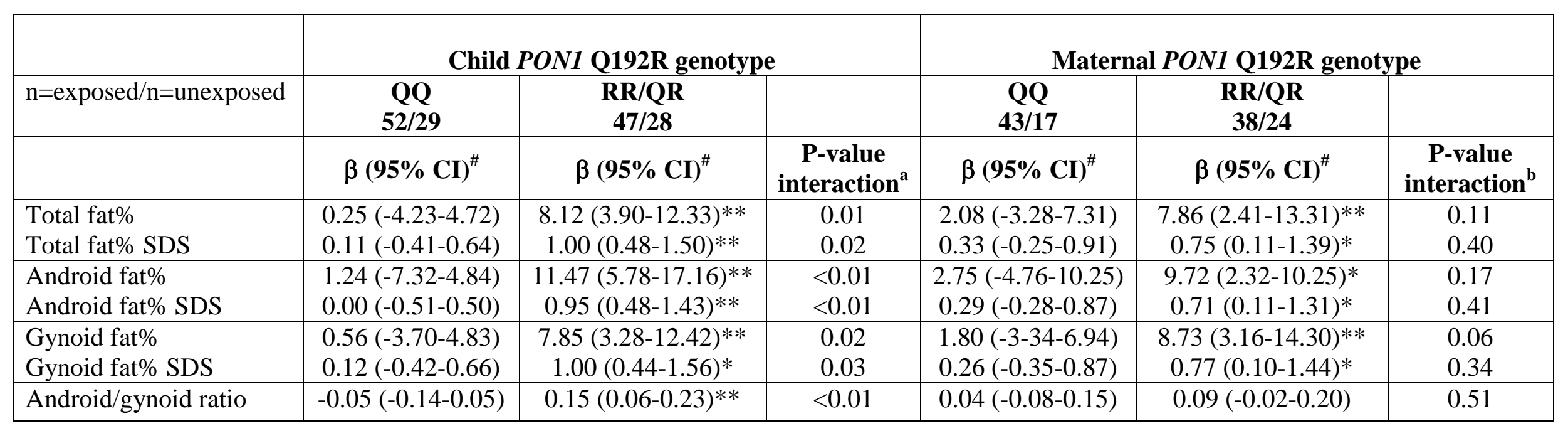

adjusted for age and sex (absolute values), SES and puberty (Y/N)

${ }^{a}$ Interaction between exposure and Child PON1 Q192R genotype

${ }^{\mathrm{b}}$ Interaction between exposure and Maternal PON1 Q192R genotype

$*$ p-value $<0.05, * *$ p-value $<0.01$ 
Figure 1 Flowchart of the cohort.

203 children examined at 3 months of age (1997-2001)

Exposed (91 boys, 77 girls), unexposed (22 boys, 13 girls)

$\longrightarrow 70$ dropouts or lost to follow-up

$\longleftarrow 44$ new control children (21 boys, 23 girls)

177 of 247 children examined at 6-11 years of age (2007-08)

Exposed (55 boys, 51 girls), unexposed (39 boys, 32 girls)

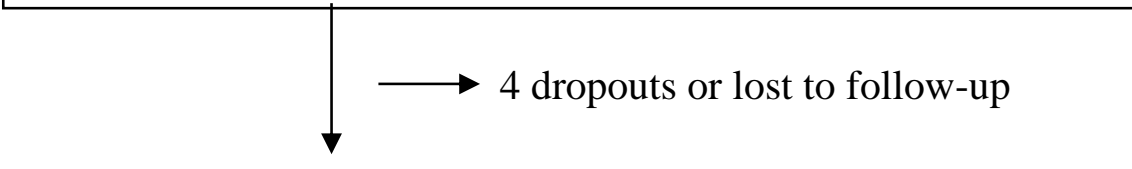

\section{Puberty examination 1}

163 of 243 children examined at 10-15 years of age (2011-12)

Exposed (55 boys, 46 girls), unexposed (36 boys, 26 girls)

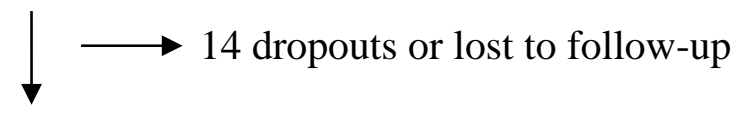

\section{Puberty examination 2}

133 of 229 children examined at 11-16 years of age (2013)

Exposed (44 boys, 39 girls), unexposed (29 boys, 21 girls) 
Figure 2 Estimated total body fat\% SDS (A), android fat\% SDS (B), gynoid fat\% SDS (C) and android/gynoid ratio (D) measured by DXA in exposed children (black) and unexposed children (dotted black) stratified by combined maternal and child PON1 Q192R genotype. SDS outcomes are adjusted for SES and puberty (yes/no) and android-gynoid ratio further adjusted for age and sex.. Open dots represent means, error bars 95\% CI. Significant p-values between exposed and unexposed $\mathrm{QR} / \mathrm{RR}$ children of $\mathrm{QR} / \mathrm{RR}$ mothers are presented as well as significant $\mathrm{p}$-values between exposed or unexposed QR/RR children and other exposed or unexposed children, respectively.
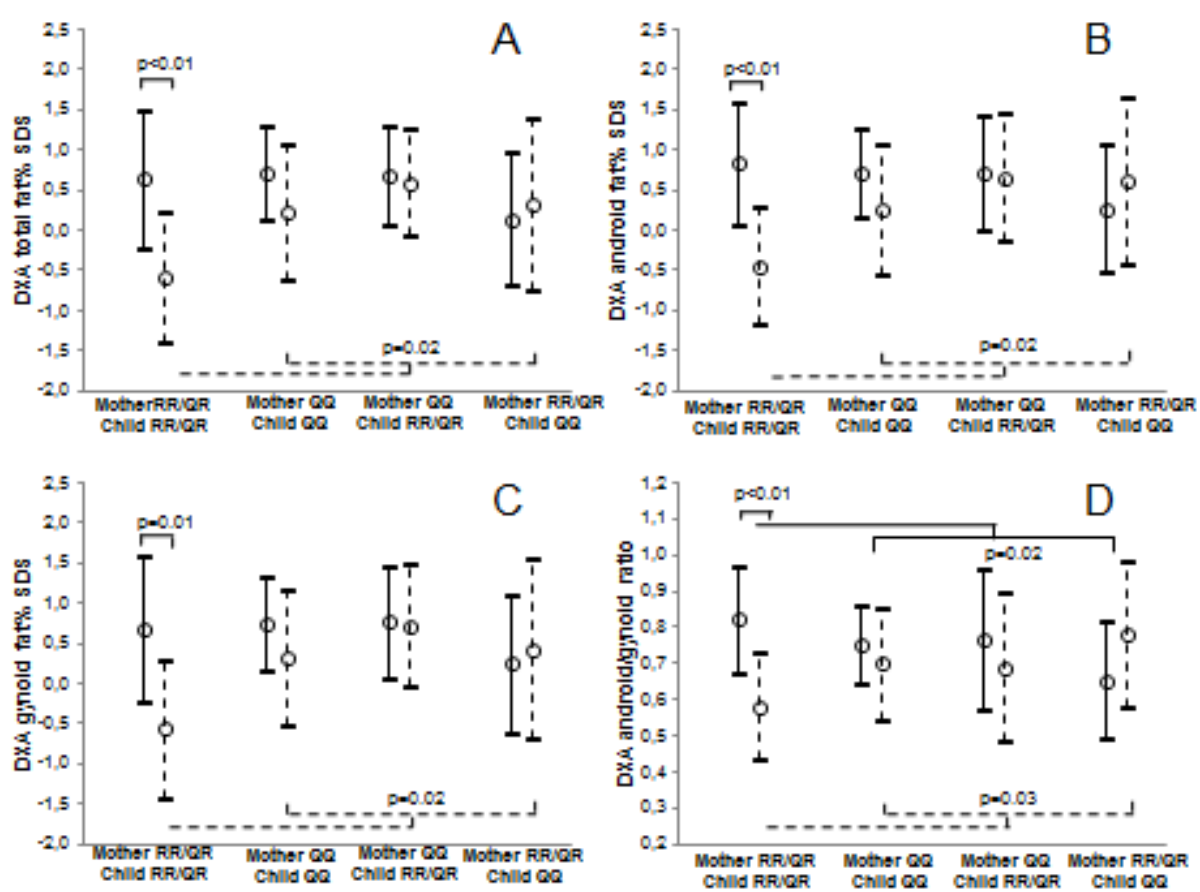